\title{
The representations of human vulnerability held by health workers - development and validation of a scale
}

\author{
Carlos Manuel Torres Almeida ${ }^{1}$ \\ Vitor Manuel Costa Pereira Rodrigues ${ }^{2}$ \\ Joaquim José Jacinto Escola ${ }^{3}$
}

\begin{abstract}
Objectives: This study's objective consisted of the construction and validation of a scale to identify the representation of human vulnerability in the health field. Method: its development was divided into three steps: a bibliographic review and exploratory interviews were conducted to establish the items and their subsequent aggregation into dimensions; evaluation by an expert committee; and pre-test. The scale's psychometric properties were evaluated based on its application to a sample of individuals (nurses, physicians, and senior nursing and medical undergraduate students). Validity, reliability, and internal consistency tests were performed. Results: the scale obtained consists of four dimensions (knowledge of intrinsic vulnerability, knowledge of extrinsic vulnerability, experience of vulnerability, and perception of vulnerability in patients). The scale presents good internal consistency with high Cronbach's alpha coefficient values. Conclusion: The Representation of Human Vulnerability in Health Workers Scale is easy to apply and presents reliable psychometric properties. It is an innovative tool that can be used in the development of studies addressing human vulnerability.
\end{abstract}

Descriptors: Scales; Validity of Tests; Vulnerability; Health.

\footnotetext{
${ }^{1}$ MSc, Professor, Escola Superior de Enfermagem, Universidade de Trás-os-Montes e Alto Douro, Portugal.

$2 \mathrm{PhD}$, Professor, Escola Superior de Enfermagem, Universidade de Trás-os-Montes e Alto Douro, Portugal.

${ }^{3}$ PhD, Professor, Escola das Ciências Humanas e Socias, Universidade de Trás-os-Montes e Alto Douro, Portugal. Researcher, Gabinete de Filosofia da Educação, Universidade do Porto, Portugal.
}

Corresponding Author:

Carlos Manuel Torres Almeida

Escola Superior de Enfermagem. Universidade de Trás-os-Montes e Alto Douro

Lugar do Tojal

Bairro Lordelo

5000-232, Vila Real, Portugal

E-mail: calmeida@utad.pt 


\section{A representação da vulnerabilidade humana em cuidadores de saúde - construção e validação de uma escala}

Objetivos: construir e validar uma escala da representação da vulnerabilidade humana em saúde. Método: para o desenvolvimento do estudo foram percorridas as etapas - revisão bibliográfica e entrevistas exploratórias para a formulação de itens e posterior agregação em dimensões, avaliação por comitê de especialistas e pré-teste. As propriedades psicométricas da escala foram avaliadas em uma amostra com 342 indivíduos (enfermeiros, médicos, estudantes finalistas de enfermagem e medicina). Foram realizados os testes de validade, fiabilidade e de consistência interna. Resultados: a escala proposta tem quatro dimensões: conhecimento da vulnerabilidade intrínseca, conhecimento da vulnerabilidade extrínseca, experiência de vulnerabilidade e perceção de situações de vulnerabilidade nos doentes, com boa consistência interna, traduzida por valores de coeficiente de alpha de Cronbach elevados. Conclusão: a Escala da Representação da Vulnerabilidade Humana é de fácil aplicação e propriedades psicométricas confiáveis. É um instrumento inovador e pode ser utilizado para o desenvolvimento de estudos sobre a vulnerabilidade humana.

Descritores: Escalas; Validade dos Testes; Vulnerabilidade; Saúde.

\section{La representación de la vulnerabilidad humana en cuidadores de la salud - construcción y validación de una escala}

Objetivos: El objetivo de este estudio consistió en la construcción y validación de una escala para la "Representación de la vulnerabilidad humana en la salud". Método: Se realizaron los siguientes pasos: Revisión bibliográfica y entrevistas exploratorias que llevaron a la formulación de Ítems y posterior agregación en dimensiones; evaluación por un comité de especialistas y un pre examen. Las propiedades psicométricas de la escala fueron evaluadas a partir de su aplicación a una muestra de 342 individuos: enfermeros, médicos y estudiantes (estos últimos finalistas en enfermería y medicina). Fueron hechos estudios de validez, de fiabilidad y consistencia interna. Resultados: Se obtuvo una escala constituida por cuatro dimensiones (Conocimiento de la vulnerabilidad Intrínseco, conocimiento de la Vulnerabilidad extrínseco, experiencia de la vulnerabilidad y percepción de situaciones de vulnerabilidad en los pacientes) con buena consistencia interna traducidas con valores de coeficiente "Alpha de Cronbach" muy elevados. Conclusiones: La "Escala de Representación de la Vulnerabilidad Humana" demostró ser de fácil aplicación y reveló propiedades psicométricas fiables, que la presentan como un instrumento innovador que permite hacer estudios generalizados sobre un tema tan importante como es el de la vulnerabilidad humana.

Descriptores: Escalas; Validez de las Pruebas; Vulnerabilidad; Salud.

\section{Introduction}

A belief in technical-scientific advancements again spotlights the myth of immortality, revealing health workers possessing ideas of omnipotence who struggle to accept the limitation of their abilities. At the same time, some patients believe that every illness can be cured and attempt to vanquish thoughts concerning the fragility and finitude inherent to them. Ignoring vulnerability, however, is counterproductive because doing so supports the occurrences of situations of vulnerability for which care is most important(1). The term vulnerability has long been used in health care, though with different meanings ${ }^{(2)}$. The polysemous nature of some words or expressions causes their meaning to change according to the situation or circumstance in which we employ them. Thus, the term "vulnerability" frequently emerges in bioethical texts to refer to the imperious need to protect the most vulnerable in the face of scientific experimentation. In the fields of public health and epidemiology, it refers to groups more vulnerable to contamination by or the propagation of certain pathologies. In this context, vulnerability emerges as a quality attributed to peoples or populations due to temporary or occasional and particular characteristics; thus, the term has an 
adjectival function(3). This is the meaning found among most studies associating vulnerability with healthcare(4-6). This is not, however, the meaning we intend to elaborate on and associate with the performance of care. Here, we refer to vulnerability "as part of the human condition"(7), a constitutive reality of humanity, and for this reason, it reveals the human being as a being that requires care ${ }^{(1)}$. The term, therefore, gains a broader, universal meaning.

The term "vulnerability" derives from the Latin term "Vulnus", which means "wound", and evokes, at least symbolically, the meaning of a bloody, painful opening that causes suffering ${ }^{(3)}$. We could simply say that vulnerability represents the irreducible susceptibility of humanity to harm, to suffering or, more bluntly, to weariness and finitude. Basically, vulnerability refers to the fragility and insecurity inherent to human beings. Such vulnerability manifests in all of humanities dimensions (ontological, ethical, natural, cultural and social)(1). The difficulty in acknowledging limitations inherent to the human being carries with it the risk of health workers departing from the true value of providing care. At the same time, as scientific knowledge, treatment and diagnosis techniques advance, patients grow increasingly dissatisfied with care delivery. In fact, vulnerability is directly associated with care "precisely because everything in the human being is vulnerable, which results in the essential and unavoidable exercise of providing care and serving him/her"(1). Thus, it is essential that those providing care be aware of the vulnerability of others, because only then can one undertake efforts to help and provide care(1). If, however, from a theoretical point of view, this relationship between vulnerability and care seems obvious, there is a need to conduct studies that transform it into scientific evidence. Some studies ${ }^{(8-9)}$ reveal that the experience of being vulnerable could be useful for health workers, including when they share experiences with patients, and such experiences could actually work as strengthening agents. Such experiences would indicate the need to understand the vulnerability of patients in relation to care that is able to satisfy them. Nonetheless, the few studies addressing this subject are qualitative studies conducted with very restricted populations, without the possibility of generalization. A study that would enable us to analyze this phenomenon more deeply with the possibility of generalization would first require the identification of the representations of human vulnerability held by health workers. But, how does one assess this representation of vulnerability?

In fact, due to the complexity of this theme and some originality in the way we sought to treat it, we were not able to find instruments that could be adapted for such a purpose in our bibliographic review. For this reason, this study's objective was to construct and validate a measurement instrument based on a theoretical construct: Representation of Human Vulnerability in Health Workers Scale (Vulnerability Scale).

\section{Method}

The study was developed in two main stages: the construction of the scale's items and the scale validation. First, based on an extensive bibliographic review and an exploratory study, we sought to define and engage a methodological path that would lead us to the construction of a scale to assess representations of human vulnerability, starting from an idealist, subjective approach with an inductive rationale, moving "from the particular to the general"(10). Data were collected through semi-structured interviews with some categories previously defined to facilitate the search for meanings and units ${ }^{(11)}$, which after depuration, would enable the construction of items and subscales of an instrument to measure the representation of human vulnerability held by health workers. With this strategy we aimed to develop a measurement instrument in which the items would not only be a result of the assumption of theoretical models proposed by various authors, but mostly, they would be based on the perceptions, experiences, and knowledge the professionals themselves have concerning the theme. In this way we would ensure a better understanding of the instrument, since its application in practice would in reality "return" to the caregivers the results that were previously extracted from them and, for this reason, would present a more familiar language and terminology.

\section{Selection of the study participants ( $1^{\text {st }}$ phase)}

Because the objective of the interviews was exploratory, we sought a diversified sample in order to obtain richer information. For this reason, a convenience sample was required because it enables easier access to people. One inclusion criterion was that healthcare providers would be uniformly distributed into two groups of professionals who most directly interact with patients (physicians and nurses). Another condition was to ensure representativeness at two different points in time: during these professionals' education (senior students with experience in clinical learning) and professionals. The sample was composed of 12 care providers (three nursing students, three medical students, three physicians and three nurses). 


\section{Selection of units of analysis and criteria to aggregate} items

In order not to skew the results and to ensure the study's ethical principles, the interviews were transcribed verbatim. Afterwards, we proceeded to the organization of content, exploration of information, organization of results and semantic interpretation. We developed a scheme to classify and code data according to the categories that were previously defined according to the theoretical framework and those that emerged after the pretest and from the content of the interviews. A total of 80 units emerged from this process. They were distributed according to the structure previously defined for the data collection instrument, to be later analyzed by experts. For that, an instrument composed of three parts was developed to identify the different components of the representations of vulnerability: (theoretical) knowledge of vulnerability, experience of vulnerability, and the perception of situations of vulnerability in patients.

The items were then submitted to the analysis of experts with doctoral degrees. Given the complexity of the theme and its transdisciplinary nature, we sought experts from various scientific fields (Psychology, Nursing, Philosophy, and Medicine). The objective of this procedure was to verify how appropriate the instrument's structure was in its different parts, how appropriate the items were for each category proposed and, finally, conduct a semantic analysis of the behavioral representation of the items' latent attributes. After the experts' analysis, 68 out of the 81 original items were kept. The items were then submitted to semantic analysis to verify whether the members of the population targeted by the instrument understood all the items. For that, four small groups (one for each section of the questionnaire) were composed to analyze the instrument item by item so that problematic items would be corrected and then tested.

A total of 67 items remained after these stages were completed (experts' analysis and semantic analysis). These items were then distributed into three parts on a self-reported scale with six levels of agreement: "totally disagree", "strongly disagree", "partially disagree", "partially agree", "strongly agree", and "totally agree".

\section{Instrument validation}

Before applying a scale, it needs to be validated, its psychometric properties need to be analyzed and, if necessary, changes and adjustments are implemented to optimize it and make it more objective. Hence, reliability and validation analyses were performed. To obtain these two types of validity, we cross-analyzed the data using exploratory factor analysis with Cronbach's alpha and correlation values among the items and total items. The following criteria were then established:

- Principal component analysis was used for the factor analysis following factor rotations to obtain a clearer and more objective factor solution, maximizing the items' factor loadings. For that purpose we chose the orthogonal method (Varimax Rotation).

- To determine the items' factors and retention, and following suggestions of various authors ${ }^{(12-17)}$, the following criteria were used: a) Kaiser criterion: factors with an eigenvalue equal to or above 1 ( $E V \geq 1)$; b) Items' factor loadings equal to or above $0.4(F L \geq 0.40)$; and c) Non-existence of relevant factor loadings (above 0.30 ) in more than one factor. In such an event and if the difference among factors were equal to or above 0.15 , we would consider deleting the item ${ }^{(16)}$; d) The percentage of variance explained by the retained factors must be at least 40\%; e) Each factor cannot present less than three items.

- To complement the reliability analysis, we established that the factor's internal consistency (Cronbach's alpha) should be at least 0.70 ; correlation of item/total items should not be less than 0.4; and the factor's internal consistency should not increase if the item was deleted.

\section{Selection of the study's participants ( $2^{\text {nd }}$ stage)}

After the inclusion criteria were defined, aiming to reduce the universe of care providers likely to belong to the target population, we opted for stratified sampling so as to obtain a representative sample according to some pre-identified variables of the studied population and also utilized non-probabilistic convenience sampling (snowball). We chose to collect data online and the instrument was available from October 2011 to April 2012. The participants received the access addresses to complete the questionnaire through e-mail. After analysis of the completed questionnaires and due to inclusion and exclusion criteria, the sample totaled 342 individuals.

To comply with ethical guidelines, a written request was sent to the management boards of the institutions involved in the study. Participation in the study was voluntary and the confidentiality of results and anonymity of the respondents were ensured. The study was approved and authorized by the institutions: 
processes 292/2011 on November 18, 2011; 1720 on October 18, 2011; and 2157 on November 4, 2011.

\section{Results}

We verified that $40.4 \%$ of the sample was composed of nursing professionals (138), 31.3\% (107) were senior students of undergraduate nursing programs, $15.8 \%$ (54) were physicians, and $12.6 \%$ (43) were senior students of undergraduate medical programs (Table 1 ).

Table 1 - Distribution of individuals by groups of professionals. Central and Northern regions of Portugal, 2011.

\begin{tabular}{lcc}
\hline \multicolumn{1}{c}{ Professions } & N & $\%$ \\
\hline Nurses & 138 & $40.4 \%$ \\
Physicians & 54 & $15.8 \%$ \\
Nursing students & 107 & $31.3 \%$ \\
Medical students & 43 & $12.6 \%$ \\
Total & 342 & $100 \%$ \\
\hline
\end{tabular}

\section{Validation studies}

Kaiser-Meyer-Olkin (KMO) and Barlett's sphericity tests were used as appropriateness criterion for factor analysis. According to the literature, the obtained KMO value of 0.863 clearly indicates the application of factor analysis. On the other hand, even though it is not as reliable, the fact that Ballet's sphericity test was significant $(p<0.05)$ indicates that the variables are correlated ${ }^{(18)}$. In a first exploratory factor analysis through the principal component method using Kaiser's criterion- eigenvalues equal to or above 1 ( $E V \geq 1)$ - we obtained a distribution of items by 16 factors that explain $64.044 \%$ of the total variance. After analysis of the Scree Plot, we opted for a new exploratory analysis by the principal component method, forcing five main components, followed by orthogonal rotation (Varimax rotation). The organization of five factors explains $41.00 \%$ of total variance (factor 1-12.39; factor 2-8.84; factor 3-8.25; factor 4-7.49 and factor 5-4.97) in its set. After the application of pre-established factor analysis criteria (which led to the elimination of some items), we obtained the following organization (Table 2).

Factor 1 emerges with 21 items, which theoretically would be grouped as experience of vulnerability. Saturation values are placed between 0.405 of item 49 ("I feel particularly vulnerable when I face social injustice") and 0.711 of item 30 ("Awareness concerning my mortality makes me think about my fragility"). Factor 2 emerges with 11 items that theoretically would express situations of vulnerability in the users of health services. Most of these items present saturation values above 0.60 . Factor 3 presents nine items. In theory, all nine items belong to the subscale designed to evaluate theoretical knowledge of vulnerability and almost all presented high saturation values (above 0.6), with the exception of item 21, which presents a factor load of 0.443. Factor 4 presents 10 items, all of them, theoretically, also belong to the subscale intended to assess theoretical knowledge of vulnerability. The factor loads of these items ranges from 0.411 for item 15 "vulnerability expresses itself in a personal diminished physical or psychological condition", to 0.623 for item 2 "The idea of vulnerability remind us we have to live with mortality". Finally, factor 5 presents five items. These items belonged to different theoretical classes and were grouped together with saturations less than those of the previous factors.

Table 2 - Matrix of components. Central and Northern regions of Portugal, 2011

\begin{tabular}{|c|c|c|c|c|c|c|c|c|c|}
\hline \multicolumn{2}{|c|}{ Factor 1} & \multicolumn{2}{|c|}{ Factor 2} & \multicolumn{2}{|c|}{ Factor 3} & \multicolumn{2}{|c|}{ Factor 4} & \multicolumn{2}{|c|}{ Factor 5} \\
\hline Item & Load & Item & Load & Item & Load & Item & Load & Item & Load \\
\hline P28 & 0.480 & P53 & 0.414 & P5 & 0.573 & $\mathrm{P} 1$ & 0.532 & P19 & 0.416 \\
\hline P29 & 0.667 & P56 & 0.458 & P6 & 0.602 & $\mathrm{P} 2$ & 0.623 & P24 & 0.515 \\
\hline P30 & 0.711 & P57 & 0.412 & P8 & 0.520 & P3 & 0.616 & P25 & -0.618 \\
\hline P31 & 0.586 & P58 & 0.505 & P9 & 0.743 & P4 & 0.631 & P36 & 0.420 \\
\hline P32 & 0.514 & P59 & 0.638 & P10 & 0.744 & $\mathrm{P} 13$ & 0.573 & P55 & 0.473 \\
\hline P33 & 0.593 & P60 & 0.605 & P11 & 0.770 & P14 & 0.609 & & \\
\hline P34 & 0.540 & P61 & 0.675 & P12 & 0.732 & P15 & 0.411 & & \\
\hline P35 & 0.584 & P62 & 0.635 & P16 & 0.406 & P22 & 0.501 & & \\
\hline P38 & 0.547 & P63 & 0.702 & P21 & 0.443 & P26 & 0.432 & & \\
\hline P39 & 0.534 & P64 & 0.537 & & & $\mathrm{P} 27$ & 0.419 & & \\
\hline P40 & 0.636 & P65 & 0.647 & & & & & & \\
\hline $\mathrm{P} 41$ & 0.441 & P67 & 0.545 & & & & & & \\
\hline P42 & 0.651 & & & & & & & & \\
\hline $\mathrm{P} 43$ & 0.633 & & & & & & & & \\
\hline P44 & 0.499 & & & & & & & & \\
\hline
\end{tabular}


Table 1 - (continuation)

\begin{tabular}{|c|c|c|c|c|c|c|c|c|c|}
\hline \multicolumn{2}{|c|}{ Factor 1} & \multicolumn{2}{|c|}{ Factor 2} & \multicolumn{2}{|c|}{ Factor 3} & \multicolumn{2}{|c|}{ Factor 4} & \multicolumn{2}{|c|}{ Factor 5} \\
\hline Item & Load & Item & Load & Item & Load & Item & Load & Item & Load \\
\hline P45 & 0.643 & & & & & & & & \\
\hline P46 & 0.596 & & & & & & & & \\
\hline P47 & 0.523 & & & & & & & & \\
\hline P48 & 0.492 & & & & & & & & \\
\hline P49 & 0.405 & & & & & & & & \\
\hline P51 & 0.594 & & & & & & & & \\
\hline
\end{tabular}

\section{Analysis of reliability and internal consistency}

An alpha of 0.920 was obtained by factor 1 , the name of which, "experience of vulnerability", was maintained. The values of item-total correlation fall between 0.422 , which corresponds to the statement "There are times that, as (prospective) health worker, I wonder whether I will be vulnerable to the suffering of others", and 0.683 obtained, which was obtained by item 30 "Awareness of my mortality makes me think about my fragility".

An alpha of 0.852 was obtained by factor 2 . Its name "perception of situations of vulnerability in patients", was also kept. Table 3 shows that the itemtotal relationships are between 0.411 and 0.635 , complying with established criteria.

In relation to factor 3 , which maintained the name "knowledge concerning extrinsic vulnerability", the analysis of results concerning the commonality of Person's item/total correlation value and also the semantic meaning indicated that item 16 of factor 3 did not meet the inclusion criteria and for this reason was eliminated. This factor, now with eight items, obtained an alpha of 0.869 . In regard to the correlation values, all items presented relatively high values.

An alpha value of 0.807 was found for factor 4, composed of 10 items, which was named "knowledge of intrinsic vulnerability". In regard to correlation values, all the items presented values above 0.4 , which was the value established as a minimum criterion.

Factor 5, obtained in the factor analysis with a grouping of five items, was problematic. Early on, it seemed difficult to find, from a theoretical point of view, a relationship for this association of items. This concern was confirmed by an alpha value of 0.130 , which is completely unacceptable, with item/total correlation values below 0.40 for all items. Given this context, we opted for excluding the items and corresponding factor.

Table 3 - Item/total correlation Cronbach's alpha reliability of the four factors. Central and Northern regions of Portugal, 2011

\begin{tabular}{|c|c|c|c|c|c|c|c|}
\hline \multicolumn{2}{|c|}{ Factor 1} & \multicolumn{2}{|c|}{ Factor 2} & \multicolumn{2}{|c|}{ Factor 3} & \multicolumn{2}{|c|}{ Factor 4} \\
\hline Item & $r$ & Item & $\mathbf{r}$ & Item & $r$ & Item & $\mathbf{R}$ \\
\hline P28 & 0.498 & P56 & 0.472 & P5 & 0.570 & $\mathrm{P} 1$ & 0.507 \\
\hline P29 & 0.601 & P57 & 0.411 & P6 & 0.570 & $\mathrm{P} 2$ & 0.560 \\
\hline P30 & 0.683 & P58 & 0.511 & P8 & 0.496 & P3 & 0.549 \\
\hline P31 & 0.573 & P59 & 0.592 & P9 & 0.746 & P4 & 0.570 \\
\hline P32 & 0.537 & $\mathrm{P} 60$ & 0.563 & $\mathrm{P} 10$ & 0.648 & P13 & 0.424 \\
\hline P33 & 0.619 & P61 & 0.635 & $\mathrm{P} 11$ & 0.745 & P14 & 0.471 \\
\hline P34 & 0.562 & P62 & 0.544 & $\mathrm{P} 12$ & 0.672 & P15 & 0.417 \\
\hline P35 & 0.619 & P63 & 0.599 & $\mathrm{P} 21$ & 0.530 & P22 & 0.436 \\
\hline P38 & 0.537 & P64 & 0.481 & & & P26 & 0.463 \\
\hline P39 & 0.514 & P65 & 0.562 & & & $\mathrm{P} 27$ & 0.423 \\
\hline P40 & 0.627 & $\mathrm{P} 67$ & 0.508 & & & & \\
\hline P41 & 0.422 & & & & & & \\
\hline P42 & 0.678 & & & & & & \\
\hline P43 & 0.574 & & & & & & \\
\hline P44 & 0.508 & & & & & & \\
\hline P45 & 0.605 & & & & & & \\
\hline P46 & 0.565 & & & & & & \\
\hline P47 & 0.578 & & & & & & \\
\hline P48 & 0.568 & & & & & & \\
\hline P49 & 0.471 & & & & & & \\
\hline \multicolumn{2}{|c|}{ Cronbach's alpha } & \multicolumn{2}{|c|}{ Cronbach's alpha } & \multicolumn{2}{|c|}{ Cronbach's alpha } & \multicolumn{2}{|c|}{ Cronbach's alpha } \\
\hline \multicolumn{2}{|c|}{0.9200} & \multicolumn{2}{|c|}{0.8522} & \multicolumn{2}{|c|}{0.8699} & \multicolumn{2}{|c|}{0.807} \\
\hline
\end{tabular}




\section{Discussion}

After proceeding with the validation and reliability analyses, we verified that the distribution of items into the four factors obtained through the principal component method diverges from the original idea that relied on three factors, although there is a clear predominance in the distribution found for the items that belong to each of the original scales (Fig. 1). Even though two factors (3 and 4) grouped items that for theoretical reasons seemed to belong to a single dimension - theoretical knowledge of human vulnerability-, the factor analysis separates the statements that show a notion of intrinsic vulnerability of the individual that results from death and disease in factor 4 , transmitting knowledge of an ontological and natural vulnerability. Factor 3 gathers statements that portray knowledge of vulnerability that emerges from exposure to another and society, which expresses theoretical knowledge of a social, ethical and cultural vulnerability. This division seems to be perfectly appropriate to our theoretical model and perhaps can facilitate analysis and understanding of the results.

We obtained four dimensions and this new distribution explains $43.77 \%$ of the total variance. All the dimensions obtained a Cronbach's alpha above 0.8 , which is considered to be "very good", while the subscale "experience of vulnerability" presents values above 0.9 , considered to be excellent. For the entire, scale an alpha of 0.936 was obtained.

\section{Representation of Human Vulnerability in Health Workers Scale}

Knowledge concerning intrinsic vulnerability

- Human experience is marked by vulnerability.

- The idea of vulnerability reminds us that we are mortal.

- Vulnerability is part of the Human Being's constitutive reality; it is a universal condition of humanity.

- Vulnerability draws attention for the perishable nature of beings, that is, the finite nature of all existing beings.

- Disease is a concrete expression of human vulnerability.

- It is in disease that individuals acquire the clearest perception of their vulnerability.

- Vulnerability expresses itself in a personal diminished physical or psychological condition.

- We become aware of our vulnerability when we face daily fatalities, such as accidents and disasters.

- Acknowledging human vulnerability/fragility is the basis of Care.

- The idea of vulnerability reminds us that we should care for others as frail individuals

Knowledge of extrinsic vulnerability

- The one who becomes closer to another becomes inevitably fragile and vulnerable.

- A human being is vulnerable because $s /$ he is exposed to another's attitudes and reactions.

- All human beings, healthy or sick, are vulnerable because they are subject to evil.

- The human being is vulnerable because $s /$ he is exposed to the risk of failure.

- Vulnerability means exposure to outrage, that is, to insult, aggression and humiliation.

- Vulnerability has to do with how easy it is for human beings to be emotionally "hurt".

- Vulnerability has to do with how easy it is for human beings to be spiritually "hurt".

- Exposure to another's vulnerability arouses feelings of fragility.

Experience of vulnerability

- Several times, a disease or disability has made me think on my personal fragility.

- The frequent thought that I can be affected by death conditions my way of life.

- Being aware of my mortality makes me think about my fragility.

- The experience of physical suffering is evidence of my fragility over the course of my life.

- I have felt vulnerable, especially in the face of experiences concerning psychological or spiritual suffering over the course of my life.

- I feel particularly vulnerable when I am powerless in the face of a difficult situation in life.

- I feel particularly vulnerable when I am powerless in the face of another person's difficulty.

- I become aware of my fragility every time I cannot achieve my objectives.

- I think about my fragility when I feel physically weak.

- When I look at someone dear to me and I glimpse signs of aging, I am led to reflect upon the vulnerability of human beings.

- I feel particularly fragile/vulnerable in situations of disease and in the face of an uncertain diagnosis.

- There are times, as a health worker, that I wonder whether I will be vulnerable to the suffering of others.

- Some negative situations or events involving family members or friends make me feel more vulnerable.

- I have found myself reflecting upon the certainty of my own death when facing the death of other people

- I am concerned that I am not able to respond to more complex situations in my professional practice.

- I feel more vulnerable when, for some reason, I have to stay away from my family.

- I feel particularly fragile/vulnerable in situations that I have to seek healthcare services. 


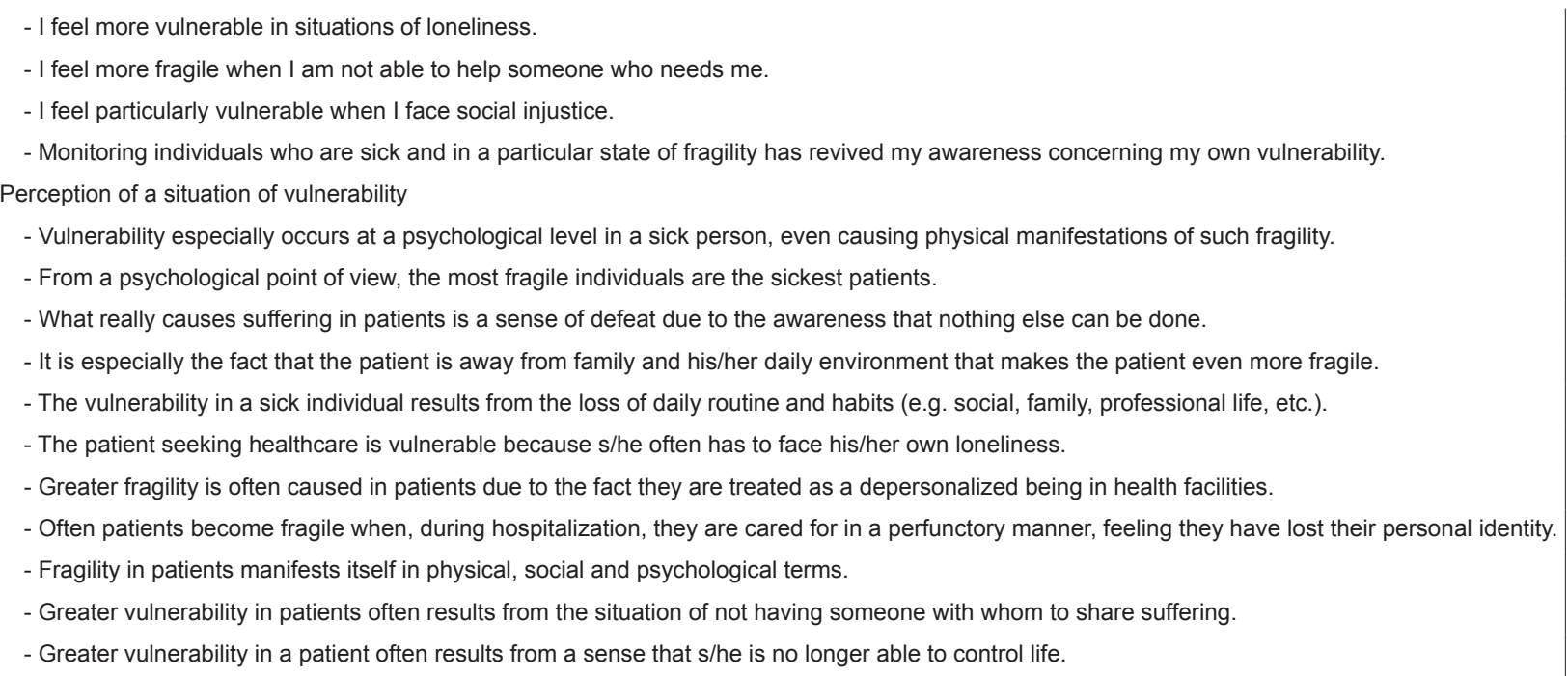

Figure 1 - Final distribution of items into the SRHVHW's dimensions. Central and Northern regions of Portugal, 2011

\section{Conclusion}

The process of constructing and validating the Representation of Human Vulnerability in Health Workers Scale enabled us to identify the representations of human vulnerability held by health providers. The scale has very reasonable initial psychometric qualities. The experts' and groups' semantic analysis, along with the pretest, indicated that the scale is easy to understand and to complete; its most complex aspect is that some items require some deliberation.

The development of this scale brings with it the possibility of studying an essential aspect of healthcare delivery, which is the relationship between vulnerability and care. It is acknowledged that human vulnerability can positively influence the delivery of care, however, a lack of assessment instruments was an obstacle impeding quantitative studies that would enable the generalization of results. This instrument can fill this gap since its application is associated with other scales addressing the care process can deepen understanding of this subject. The scale provided a profile of the representation of human vulnerability held by health workers, revealing strengths and weaknesses that need to receive attention in order to support the achievement of a true Care paradigm.

\section{References}

1. Waldow VR; Borges RF. The Caregiving Process In Vulnerability Perspetive. Rev. Latino-Am. Enfermagem. 2008 Jul-Ago; 16(4):765-71.

2. Nichiata LYI, Bertolozzi MR, Takahashi RF, Fracolli
LA. The use of "Vulnerability" concept in the nursing area. Rev. Latino-Am. Enfermagem. 2008 SeptOct; 16(5): 923-8.

3. Neves MCP. Sentidos da vulnerabilidade: Características, condição, princípio. Rev Bras Bioética. 2006;2(2):157-72.

4. Brito DMS, Galvão MTG, Pereira. Markers of vulnerability for cervical cancer in HIV-infected women. Rev. Latino-Am. Enfermagem. 2011 June; 19(3):500-7. 5. Pavarini SCI, Barha JNB, Mendidondo MSZ, Filizola CLA, Filho JFP, Santos AA. Family and social vulnerability: a study with octogenarians. Rev. Latino-Am. Enfermagem. 2009 June;17(3):374-9.

6. Nakamura E, Egry EY, Campos CMS, Nichiata LYI; Chiesa AM, Takahashi RF. The potential of an instrument to identify social vulnerabilities and health needs: collective health knowledge and practices. Rev. LatinoAm. Enfermagem. 2009April;17(2):253-8.

7. Renaud I. Fragilidade e vulnerabilidade. Rev Portuguesa Bioética. 2005;39:405-16.

8. Malterud K, Fredriksen L, Gjerde MH. When doctors experience their vulnerability as beneficial for the patients. Scand J Primary Health Care. 2009:27(2):8590.

9. Sorlie V, Torjuul K, Ross A, Kihlgren M. Satisfied patients are also vulnerable patients: Narratives from an acute care ward. J Clin Nurs. 2006;15(10):1240-6.

10. Feldman H. Theorical Framework. In: LobiondoWood G, Harber J. Nursing research: Methods, critical appraisal, and utilization. 4th ed. St Louis (MO): Moby; 1998. p. $135-54$. 
11. Lessard-Hébert M, Goyette G, Boutin, G. Investigação qualitativa: Fundamentos e práticas. Lisboa: Instituto Piaget; 1994. 184 p.

12. Brown T. Confirmatory fator analyses for applied Research. New York: The Guiford Press; 2006. 475 p.

13. Blunch $\mathrm{N}$. Introduction to structural equation modelling using SPSS and AMOS. London: Sage; 2008. $270 \mathrm{p}$.

14. Henson RK, Roberts JK. Exploratory fator analysis reporting practices in published psychological research: Common errors and some comment on improved practice. Educ Psychol Measure. 2006;66(3):393-416.

15. Preacher KJ, MacCallum RC. Repairing Tom Swift's electric fator analysis machine. Understanding Statistics. 2003;2:13-32.

16. Worthington RW, Whittaker TA. Using exploratory and confirmatory fator analysis in scale development research: A content analysis and recommendations for best practices. Counse Psychologist. 2006;34(6):80638.

17. Hair J, Black W, Babin B, Anderson R. Multivariate Data Analysis. 7th Ed. New Jersey: Pearson Educational; 2006. 785 p.

18. Maroco J. Análise Estatística com utilização do SPSS. 3a ed. Lisboa: Edições Sílabo; 2007. 822 p. 